\title{
Jahrestagung 1990
}

Die Jahrestagung fand vom 3. bis 6. Oktober in Zürich statt. Der Vorsitzende eröffnete die Mitgliederversammlung am 3. Oktober dem Tag der deutschen Einheit - mit folgenden Worten:

„Unversehens ist dies zu einem Tag geworden, für den das Wort ,historisch' nicht zu anspruchsvoll ist. Fünfundvierzig Jahre deutscher Teilung sind seit der Mitternacht Vergangenheit. Was damit Realität geworden ist, wagen wir kaum schon zu glauben. Politische Tatsachen, die über Jahrzehnte ein Teil unserer Weltorientierung waren, gezwungenermaßen, sind nun mit einem Schlag fortgefallen. Das berührt nicht nur Deutschland. Denn die Verfassung Deutschlands ist ja, durchaus nicht zum deutschen Vorteil, fast immer zugleich ein Element der Gesamtverfassung Europas gewesen; ich brauche dafür nur die Jahreszahlen 1648 und $1815 \mathrm{zu}$ nennen. Heute endet mit der Teilung Deutschlands zugleich auch die Teilung Europas. Die Verträge, die dies bewirkt haben, sind angelegt als Bausteine eines europäischen Friedensinstruments, eines Friedensinstruments, dem wir Erfolg wünschen und vor allem Dauer. Ein herausgehobener Tag von wahrhaft historischer Bedeutung ist der heutige Tag über das alles hinaus aber auch deshalb, weil der Geist, der die Überwindung der Versklavung einer Hälfte Europas ermöglicht hat, seine Stärke aus der werbenden Kraft der Prinzipien einer rechtsstaatlichen Verfassung bezogen hat. Auch das geht nicht nur Deutschland an, und wen ginge es stärker an als den Verfassungsrechtler?

Als wir diese Tagung planten, hat niemand solche Ereignisse voraussehen können. Aber ich meine, der Zufall, der es bewirkt hat, daß die Vereinigung der Deutschen Staatsrechtslehrer gerade heute zusammentritt - und gerade zu ihrer fünfzigsten Tagung - ist ein sinnvoller Zufall. Natürlich vergesse ich nicht, daß wir uns hier in Zürich befinden, in der Schweiz, unter Freunden zwar, denen wir für ihre Gastfreundschaft herzlich dankbar sind, aber eben doch als Gäste. Und wir sind uns alle natürlich auch dessen bewußt, daß diese Vereinigung Angehörige verschiedener Nationen umfaßt; gerade daraus zieht sie ja einen Teil ihrer wissenschaftlichen Kraft. Beides verpflichtet, wo es um nationale Angelegenheiten geht, zur 
Zurückhaltung. Aber daran brauche ich nicht zu erinnern: denn auch für uns deutsche Mitglieder ist dies zwar ein Tag der Freude, aber gewiß nicht ein Tag des Überschwangs.

Ein Tag der Freude, tiefinnerlicher Freude, gewiß, die unsere Freunde mit uns teilen werden, und zugleich auch ein Tag des Dankes, des Rückblicks, der Selbstbesinnung. Zu Überschwang dagegen ist für uns schon deshalb kein Anlaß, weil zu viel Schweres zurückliegt und in diesem Augenblick erinnert sein will. Ich habe es, wie viele von uns, immer als höchst belastend empfunden, daß die Folgen des von Deutschland zu verantwortenden Krieges von einem Viertel des Volkes, stellvertretend für alle, getragen werden mußten - und daß wir nichts daran ändern konnten. Viele haben so empfunden, und ich denke, daß diese Wunde - griechisch: dieses Trauma - auch bei denen seine Wirkungen getan hat, die die Wunde nicht wahrhaben wollten. Jetzt ist es möglich geworden, Hand anzulegen, die Ungerechtigkeit auszuräumen. Viel wird zu tun sein; nicht nur beim Aufbau der Verwaltung und Wirtschaft, sondern vor allem auch zur Heilung der Schäden, die das System an den Menschen hinterlassen hat. Aber mit dem allen ist doch jetzt wenigstens ein Anfang gemacht.

Es ist, sagte ich, auch ein Tag des Dankes. Dank schulden wir jenen deutschen Landsleuten, die im Herbst letzten Jahres die friedliche Revolution in der DDR in Bewegung gesetzt haben. Sie haben in ihrer ganz unpathetischen Weise der Sache der Freiheit einen Dienst geleistet, der weit über Deutschland hinaus trägt. Dank muß man auch den Staatsmännern sagen, in Ost und West und auch in Deutschland, die die Wege zur jetzigen Lösung gebahnt haben. Und wir sollten nicht vergessen, Gott zu danken dafür, daß sich diese gewaltige Umwälzung so ganz und gar friedlich vollziehen konnte."

Anschließend gedachten die Versammelten der im vergangenen Jahr verstorbenen Kollegen Hans Ulrich Scupin und Dieter Subr. Die Vereinigung wird ihr Andenken in Ehren halten. - Vier Kollegen traten seit der letzten Tagung bei, so daß diese nunmehr 360 Mitglieder zählt. Die nächste Tagung soll in der ersten Oktoberwoche 1991 in Gießen stattfinden, die Tagungen 1992 und 1993 in Bayreuth und Mainz. Der amtierende Vorstand - Klaus Vogel, Volkmar Götz und Hans-Jürgen Papier - wurde in geheimer Wahl wiedergewählt.

Die Vorträge und Diskussionen fanden in der Aula der Universität statt, einem repräsentativen, schön gestalteten Raum, demselben, in dem 1945 Winston Churchill die Jugend Europas zu dessen Vereinigung aufgerufen hatte: "Let Europe arise!" Diesem historischen 
Bezug zum ersten Tagungsthema gesellte sich durch die in der Aula aufgestellte Büste des berühmten Staats- und Verwaltungsrechtlers Fritz Fleiner, vormaligen Rektors der Universität Zürich, ein Bezug zum zweiten Tagungsthema hinzu. Vor Eintritt in die Beratungen begrüßte der Kollege Walter Haller als Dekan der gastgebenden Rechts- und Staatswissenschaftlichen Fakultät die Tagungsteilnehmer. Den Vorsitz führte Klaus Vogel; Volkmar Götz und Hans-Jürgen Papier leiteten die Aussprachen.

Die wissenschaftliche Tagung wurde umrahmt von einem glanzvollen Beiprogramm. Es begann mit einer Einführung in die Stadtgeschichte Zürichs im alten Rathaus der Stadt mit anschließender Stadtführung, setzte sich fort in zwei großzügigen Empfängen - am Mittwochabend durch den Rektor der Universität in deren Lichthof, am Donnerstagabend im Stadthaus durch den schweizerischen Bundespräsidenten, den Regierungsrat des Kantons Zürich und den Stadtpräsidenten - und fand seinen krönenden Höhepunkt in einem festlichen "Nachtessen“ mit anschließendem Tanz im historischen Zunfthaus "Zur Meisen“. Am Samstag klang dann die Tagung aus mit einem Ausflug zur Königsfeldener Klosterkirche und anschließend nach Schloß Lenzburg, wo die Teilnehmer Gäste des Regierungsrates des Kantons Aargau waren.

Für die sorgfältige und liebevolle Vorbereitung der Tagung ebenso wie für deren hervorragende Organisation schuldet die Vereinigung Georg Müller, seinen Züricher Kollegen, ihren Damen und Herrn Präsidenten des Bezirksgerichts Hans Peter Weber sowie allen Helfern Georg Müllers besonderen Dank.

K. V. 
